\title{
High-Pressure Phase Behavior for Poly(ethylene glycol) and 1,1,1,2- Tetrafluorethane Systems
}

\author{
Marcela Oliveira Meneses, ${ }^{\dagger}$ Claudio Dariva, ${ }^{\dagger}$ Gustavo Rodrigues Borges, ${ }^{\dagger}$ Sandro R. P. da Rocha, ${ }^{\ddagger}$ \\ Marcelo Santiago Zabaloy, ${ }^{\S}$ and Elton Franceschi*,† \\ ${ }^{\dagger}$ Instituto de Tecnologia e Pesquisa-ITP, Programa de Pós-Graduação em Engenharia de Processos PEP/UNIT, Campus Farolândia, \\ Av. Murilo Dantas, 300, Aracaju, SE 49032-490, Brazil \\ ${ }^{\ddagger}$ Pharmaceutics \& Chemical and Life Science Engineering, Virginia Commonwealth University, Richmond, Virginia 23298, United \\ States \\ ${ }^{\S}$ Planta Piloto de Ingeniería Química, Universidad Nacional del Sur - CONICET, CC 717, 8000 Bahía Blanca, Argentina
}

ABSTRACT: The development of polymeric systems for drug delivery has received attention with the aim of producing new systems as an alternative to conventional drug therapy. The design of new systems for this purpose in a compressed medium requires a knowledge of the phase behavior for the polymeric matrix in the high-pressure fluids. This work reports the phase equilibrium experimental data of binary systems involving poly(ethylene glycol) (PEG) with molecular weights of 1000 and $2000 \mathrm{~g} \cdot \mathrm{mol}^{-1}$ and 1,1,1,2-tetrafluoroethane (HFA-134a). The experimental data were obtained in a high-pressure variable-volume viewing cell based on the static synthetic method at temperatures from 287.4 to $334.2 \mathrm{~K}$, pressures of up to $29.81 \mathrm{MPa}$, and a PEG concentration in the range of 1 to $7 \mathrm{wt} \%$. Liquid-liquid equilibrium,

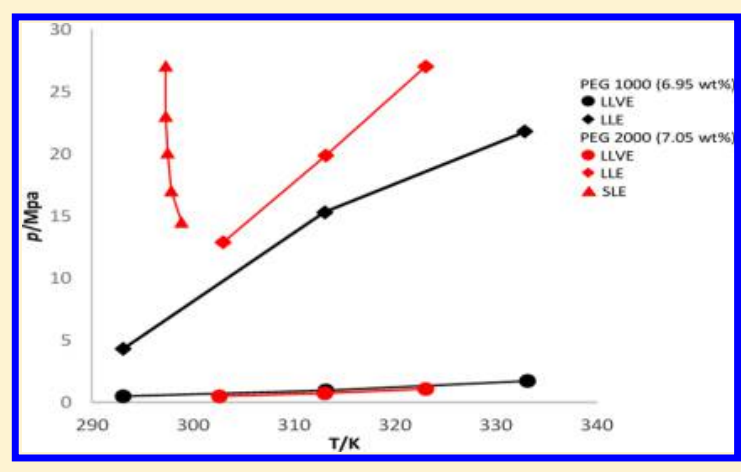
liquid-liquid-vapor equilibrium, and, in some cases, solid-liquid equilibrium were observed under the experimental conditions of pressure, temperature, and compositions investigated. The experimental results show that temperature and pressure have significant influences on the solubility of PEG in HFA-134a. The solid-phase formation for the system PEG + HFA-134a, in the range of values investigated for temperature, pressure, and compositions, is influenced by the molecular weight of the polymer.

\section{INTRODUCTION}

Interest in the development of polymeric systems for drug delivery is growing. In recent years, anchored by genetic engineering and biotechnology, many studies have been conducted to produce new systems as an alternative to conventional drug therapy. ${ }^{1-5}$

The production of particles with size control and distribution has been the subject of various research for the development of biodegradable and/or biocompatible polymeric nanoparticles. Such investigations are related to the search of formulations for the controlled release of active principles or to the use of more appropriate routes of administration.

The traditional techniques for producing the abovementioned particles have limitations that include the excessive use of solvent, resulting in large residual concentrations of these solvents in the final product, chemical and thermal degradation of the solute, and difficulties in controlling the size and distribution of the particles during processing. ${ }^{6-10}$

High-pressure subcritical or supercritical fluids have been used frequently as media to produce micro/nanoparticles of various biodegradable polymers for drug delivery applications. This process shows appreciable properties such as mass transfer, near-zero surface tension, and effective solvents elimination. $^{11}$
In these systems, the goal of the biopolymer particle formation process is to encapsulate a biologically active ingredient within a polymer matrix to make possible the further controlled release of such an ingredient to a target site. $^{12,13}$

The majority of the investigations on high-pressure polymeric nanoparticles, reported in the literature, deals with a carbon dioxide precipitating agent. ${ }^{9,10}$ The phase behavior of the chosen polymer and pharmaceutical drug in the highpressure solvent plays a crucial role in the design of an efficient controlled -release system. ${ }^{12,13}$ Because of the very low solubility of the majority of polymers in carbon dioxide, experimental data of phase equilibria of polymeric system in this gas were measured with organic solvents as entrainers. ${ }^{14-18}$

Poly(ethylene glycol)s (PEGs) also exhibit low solubility in carbon dioxide; i.e., the system has a wide heterogeneity region. ${ }^{19,20}$ Like the other polymers, PEG's solubility in $\mathrm{CO}_{2}$ is strongly dependent on its molecular weight. ${ }^{21,22}$ Other biocompatible gases, such as hydrofluoroalkanes (HFAs), whose mixtures with polymers are expected to have larger homogeneity regions, could also be explored in this area.

Received: February 15, 2017

Accepted: April 25, 2017 
The HFAs are refrigerant gases containing hydrogen, fluorine, and carbon in their structure. The HFAs are used in industry as solvents, as aerosol propellants, as fire extinguisher gases, as blowing agents in the manufacture of foams, and, finally, as refrigerants in air conditioning devices, refrigerators, and heat pumps. ${ }^{23,24}$ HFAs were introduced in the pharmaceutical industry to replace CFCs (chlorofluorocarbons). Because CFCs affect the ozone layer, they have been banned in medicines since the year 2005. Refrigerant 1,1,1,2tetrafluorethane is an HFA that is also known as HFA-134a and/or HFC-134a and/or R-134a. ${ }^{25}$

In the pharmaceutical and cosmetics areas, PEG has been used in a wide variety of applications because of properties such as its solubility in water and organic solvents, low toxicity, high lubricity, high stability, and low volatility. ${ }^{26-28}$ PEG has been used frequently in the formulation of capsules and suppositories designed for drug release control in the human body. ${ }^{29,30}$

In this work, the phase behavior of systems composed of refrigerant gas HFA-134a and of biocompatible and biodegradable polymer PEG was experimentally investigated. Phase transitions were determined over a range of temperature, pressure, and polymer concentration. Liquid-liquid equilibrium (LLE), liquid-liquid-vapor equilibrium (LLVE), and, in some cases, liquid-solid equilibrium (LSE) were observed over the experimental ranges of conditions investigated.

\section{EXPERIMENTAL SECTION}

2.1. Materials. HFA-134a gas ( $99.9 \%$ purity) was purchased from DuPont (Holland). PEG-1000 $\left(M_{\mathrm{w}}=1000 \mathrm{~g} \cdot \mathrm{mol}^{-1}\right.$, density at $293 \mathrm{~K}=1.2 \mathrm{~g} \cdot \mathrm{cm}^{-3}$, polydispersity index about 1.1 , melting point $=309-313 \mathrm{~K})$ was provided by Fluka. PEG-2000 $\left(M_{\mathrm{w}}=2000 \mathrm{~g} \cdot \mathrm{mol}^{-1}\right.$, density at $293 \mathrm{~K}=1.21 \mathrm{~g} \cdot \mathrm{cm}^{-3}$, polydispersity index about 1.2 , melting point $=309-313 \mathrm{~K}$ ) was purchased from Sigma. Both PEGs have a vapor pressure of less than $1.0 \times 10^{-6} \mathrm{MPa}$ at $293 \mathrm{~K}$. Solvent HFA-134a and both polymers were used without further purification.

2.2. Phase Equilibria Apparatus and Procedure. All experimental data of the measured phase equilibria were recorded in a variable volume view cell based on the static synthetic methodology. An apparatus description can be found in the literature. ${ }^{31-33}$

The experimental procedure is started by loading a precise mass of PEG into the equilibrium cell (precision of $10^{-4} \mathrm{~g}$ ). The cell is then closed and connected to the experimental unit, and HFA-134a is made to flow at low pressure, slowly, through the cell to remove residual air. Then, a syringe pump is used to load HFA-134a with a precision of $0.01 \mathrm{~mL}$. The mixture is stirred in the cell with the help of a magnetic stirrer. The temperature controller is turned on, and the pressure of the system is increased until a single phase is observed within the cell. The system is maintained at this point for about $30 \mathrm{~min}$ for stabilization. For the liquid-liquid and liquid-liquid-vapor acquisition data, the pressure is slowly decreased at a rate of around $0.3-0.4 \mathrm{MPa} \cdot \mathrm{min}^{-1}$ until the appearance of a second phase. The value of the measured pressure is recorded, and the equilibrium data was obtained in triplicate for each temperature and composition. The uncertainty in the measured pressure is estimated to be lower than $\pm 0.08 \mathrm{MPa}$. The mass of HFA-134a loaded into the cell is computed from the difference between the initial volume and the final volume occupied by the solvent within the syringe pump. The estimated composition uncertainty is around wt \% 0.01. Temperature is controlled to within $\pm 0.5 \mathrm{~K}$.
To obtain the solid-fluid transition data, a methodology similar to that described by McHugh and Krukonis ${ }^{34}$ and Favareto et al. $^{35}$ was used. The experimental procedure is analogous to that described above for fluid-fluid transitions except that in this case, for solid-fluid equilibrium measurements, the temperature is varied while the pressure remains constant.

\section{RESULTS AND DISCUSSION}

3.1. System HFA-134a + PEG-1000. Table 1 shows the phase equilibrium data for the system HFA-134a + PEG-1000,

Table 1. Phase Equilibrium Data for the System HFA-134a + PEG-1000 ${ }^{a}$

\begin{tabular}{|c|c|c|c|}
\hline \multicolumn{2}{|c|}{ LLE } & \multicolumn{2}{|c|}{ LLVE } \\
\hline$T / \mathrm{K}$ & $\mathrm{P} / \mathrm{MPa}$ & $T / \mathrm{K}$ & $\mathrm{P} / \mathrm{MPa}$ \\
\hline \multicolumn{4}{|c|}{ wt \% PEG: 1.40} \\
\hline \multirow[t]{3}{*}{333.15} & $8.24 \pm 0.08$ & 293.0 & $1.03 \pm 0.03$ \\
\hline & & 313.0 & $1.56 \pm 0.01$ \\
\hline & & 333.3 & $2.13 \pm 0.03$ \\
\hline \multicolumn{4}{|c|}{ wt \% PEG: 2.49} \\
\hline 302.7 & $1.20 \pm 0.04$ & 293.2 & $0.64 \pm 0.03$ \\
\hline 313 & $5.76 \pm 0.06$ & 303.2 & $0.87 \pm 0.04$ \\
\hline \multirow[t]{2}{*}{333.3} & $12.76 \pm 0.04$ & 313.2 & $1.18 \pm 0.01$ \\
\hline & & 333.3 & $1.85 \pm 0.02$ \\
\hline \multicolumn{4}{|c|}{ wt \% PEG: 4.74} \\
\hline 293.8 & $2.63 \pm 0.03$ & 293.8 & $0.67 \pm 0.02$ \\
\hline 313.2 & $12.91 \pm 0.04$ & 313.2 & $1.45 \pm 0.03$ \\
\hline 333.1 & $21.32 \pm 0.06$ & 332.8 & $1.97 \pm 0.02$ \\
\hline \multicolumn{4}{|c|}{ wt \% PEG: 6.95} \\
\hline 293.1 & $4.29 \pm 0.03$ & 293.1 & $0.48 \pm 0.02$ \\
\hline 313.1 & $15.30 \pm 0.03$ & 313.2 & $0.97 \pm 0.04$ \\
\hline 332.9 & $21.78 \pm 0.03$ & 333.2 & $1.71 \pm 0.03$ \\
\hline
\end{tabular}

at different PEG concentrations (1.40, 2.49, 4.74, and $6.95 \mathrm{wt}$ $\%)$. At higher concentrations, it was found that PEG-1000 is not soluble in HFA-134a, within the temperature and pressure ranges investigated in our experiments (293 to 333 ) $\mathrm{K}$ and at pressure of up to $30 \mathrm{MPa}$, which is the maximum operating pressure of the experimental apparatus. In this system, LLE and LLVE were observed. The transition pressure values reported in Table 1 are average values of at least two duplicate runs and are presented together with the corresponding standard deviation values.

Figure 1 shows a $P-T$ projection of experimental solubility measurements obtained for the HFA-134a + PEG-1000 system at 293, 303, 313, and $333 \mathrm{~K}$ and a PEG concentration of 2.49 wt \%. In the region below the LLVE curve (squares), there are two phases: a vapor and a liquid phase. The area between the LLVE curve and the LLE curve (rhombuses) is the liquidliquid immiscibility region, where two distinct liquid phases are present. Above the LLE curve, the system is homogeneous (single liquid phase). As can be observed in Figure 1, an increase in temperature leads to a decrease in PEG-1000 solubility, and an increase in pressure promotes an increase in glycol solubility. Figure 1 shows that if,while following a path on the homogeneous region the system enters the heterogeneous region then at some temperature and pressure values a higher pressure will take (when keeping the temperature 


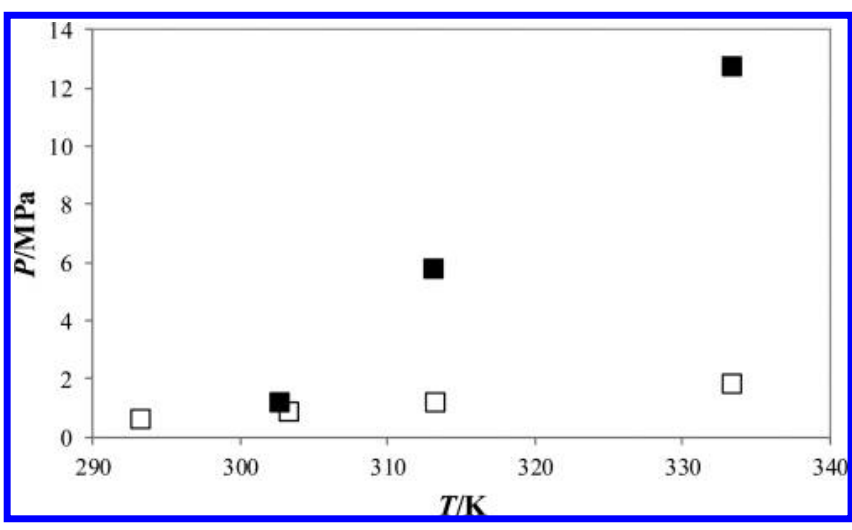

Figure 1. Phase equilibrium data for the HFA-134a + PEG-1000 system at PEG concentration $=2.49$ wt $\%$. $(\boldsymbol{\square})=$ LLE and $(\square)=$ LLVE.

constant) the system back into the homogeneous region (single phase of the liquid type).

In general, as in the case of Figure 1 and in the other figures in the article with a $P-T$ projection, the systems involving polymers have a region that exhibits liquid-liquid equilibrium of the lower critical solution temperature type (LCST curve).$^{36-38}$ In this region, the characteristic of the system is an immiscibility area where the increase in the temperature at constant pressure leads to a decrease in the solubility of the polymer into solvent. Thus, in order to keep the system in a single phase by increasing the temperature, it is also necessary to increase the pressure, resulting in a positive slope of the liquid-liquid equilibrium curve. As described in the literature, the LCST behavior is dependent on the entropy of the system, which is an effect of the difference in free volume between the solvent and PEG, suggesting that the intermolecular forces between polymer and solvent are temperature-dependent. ${ }^{39,40}$

Figure 2 shows the LLE and LLVE curves for the system HFA-134a + PEG-1000 in the temperature range from 293 to $333 \mathrm{~K}$ for all studied compositions.

As shown in Figure 2, as the PEG concentration increases, liquid-liquid and vapor-liquid-liquid curves merge at a lower temperature. Also, the liquid-liquid curve slope becomes more pronounced, increasing the region of liquid-liquid immiscibility.

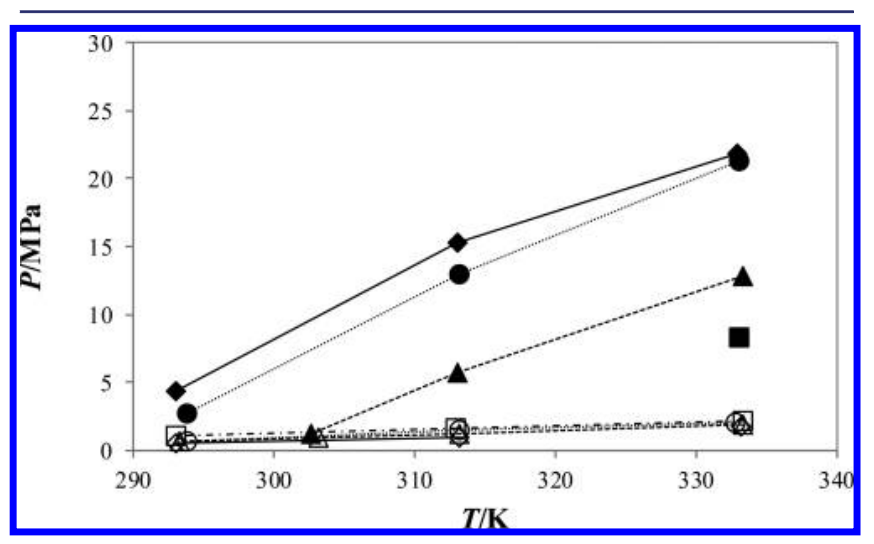

Figure 2. Phase equilibrium data for the HFA-134a + PEG-1000 system at different PEG concentrations: (ם) LLE and ( $\square$ ) LLVE, PEG $=1.40$ wt \%; $(\boldsymbol{\Delta})$ LLE and $(\triangle)$ LLVE, PEG $=2.49$ wt \%; $(\bullet)$ LLE and $(\bigcirc)$ LLVE, PEG $=4.74$ wt \%; $(\diamond)$ LLE and $(\diamond)$ LLVE, PEG $=6.95 \mathrm{wt} \%$. Lines through data points are only to guide the eye.
Otherwise, at the highest temperature, i.e., at $333 \mathrm{~K}$ (Figure $3 \mathrm{C}$ ), and also at PEG-1000 = 1.4 wt \%, both LLVE and LLE

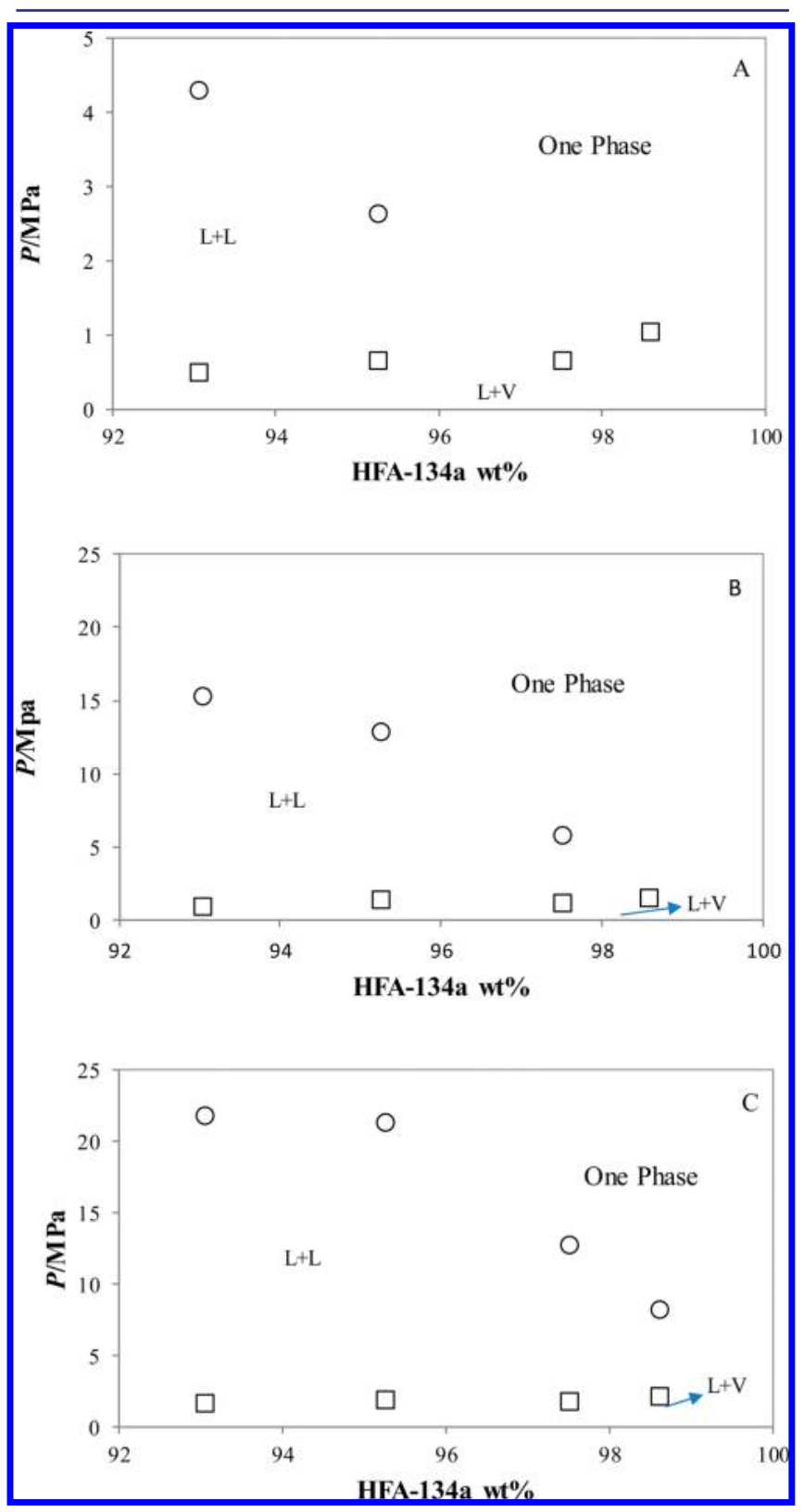

Figure 3. Phase equilibrium data for the HFA-134a + PEG-1000 system at (A) $293 \mathrm{~K}$, (B) $313 \mathrm{~K}$, and (C) $333 \mathrm{~K}$. LLE = O and LLVE = $\square$.

transitions were found. Figure 3 suggests that as the temperature increases, the point where the LLE branch of higher solvent concentration and the LLVE locus meet is shifted to the right, i.e, to a higher solvent concentration. In other words, at a set high solvent concentration, the LLE transition is easier to detect if the temperature is sufficiently high.

Figures 1 and 2 suggest that, at a given overall PEG-1000 concentration, the LLE and LLVE loci meet at some point. If that is the case, then such a point would be a LLVE point belonging to the phase envelope of the constant composition plot (= isopleth plot).

3.2. System HFA-134a + PEG-2000. The experimental measurements for system HFA-134a + PEG-2000 were 
performed at PEG concentrations of $1.39,2.80,3.89$, and 7.04 wt $\%$. Table 2 shows the phase equilibrium data for system

Table 2. Phase Equilibrium Data for System HFA-134a + PEG-2000 ${ }^{a}$

\begin{tabular}{|c|c|c|c|c|c|}
\hline \multicolumn{2}{|r|}{ LLE } & \multicolumn{2}{|c|}{ LLVE } & \multicolumn{2}{|c|}{ LSE } \\
\hline$T / \mathrm{K}$ & $\mathrm{P} / \mathrm{MPa}$ & $T / \mathrm{K}$ & $\mathrm{P} / \mathrm{MPa}$ & $T / \mathrm{K}$ & $\mathrm{P} / \mathrm{MPa}$ \\
\hline \multicolumn{6}{|c|}{ wt \% PEG: 1.39} \\
\hline 303.1 & $1.56 \pm 0.06$ & 303.1 & $0.46 \pm 0.02$ & $287.4 \pm 0.1$ & 14.06 \\
\hline 313.1 & $6.42 \pm 0.03$ & 313.1 & $0.58 \pm 0.02$ & $290.7 \pm 0.3$ & 5.98 \\
\hline \multirow[t]{2}{*}{333.2} & $14.91 \pm 0.03$ & 333.2 & $1.21 \pm 0.01$ & $291.8 \pm 0.2$ & 4.04 \\
\hline & & & & $293.6 \pm 0.3$ & 2.53 \\
\hline \multicolumn{6}{|c|}{ wt \% PEG: 2.80} \\
\hline 303.1 & $8.25 \pm 0.05$ & 303.4 & $0.61 \pm 0.01$ & 293.8 & 23.07 \\
\hline 313.1 & $13.68 \pm 0.04$ & 313.1 & $0.94 \pm 0.02$ & $294.7 \pm 0.2$ & 14.04 \\
\hline \multirow[t]{2}{*}{333.3} & $24.93 \pm 0.05$ & 333.2 & $1.47 \pm 0.02$ & $295.7 \pm 0.2$ & 10.08 \\
\hline & & & & $296.6 \pm 0.4$ & 8.05 \\
\hline \multicolumn{6}{|c|}{ wt \% PEG: 3.89} \\
\hline 302.8 & $11.83 \pm 0.01$ & 303.2 & $0.77 \pm 0.03$ & $295.5 \pm 0.4$ & 27.16 \\
\hline 313.2 & $18.67 \pm 0.05$ & 313.2 & $1.07 \pm 0.02$ & $295.4 \pm 0.3$ & 22.06 \\
\hline \multirow[t]{3}{*}{333.2} & $29.81 \pm 0.03$ & 333.3 & $1.96 \pm 0.03$ & $295.3 \pm 0.2$ & 17.02 \\
\hline & & & & $296.9 \pm 0.1$ & 15.04 \\
\hline & & & & $297.6 \pm 0.1$ & 13.04 \\
\hline \multicolumn{6}{|c|}{ wt \% PEG: 7.04} \\
\hline 303.0 & $12.89 \pm 0.05$ & 302.7 & $0.45 \pm 0.02$ & $298.9 \pm 0.3$ & 14.52 \\
\hline 313.1 & $19.83 \pm 0.02$ & 313.1 & $0.69 \pm 0.04$ & $297.8 \pm 0.4$ & 17.04 \\
\hline \multirow[t]{3}{*}{323.0} & $27.01 \pm 0.04$ & 323.0 & $1.06 \pm 0.04$ & $297.5 \pm 0.3$ & 20.07 \\
\hline & & & & $297.3 \pm 0.2$ & 23.01 \\
\hline & & & & $297.3 \pm 0.2$ & 27.05 \\
\hline
\end{tabular}

${ }^{a} u(T)=0.5 \mathrm{~K}, u($ wt \%) $=0.01$, and $u(p)=0.08 \mathrm{MPa}$. $u$ is the uncertainty in the measurement.

HFA-134a + PEG-2000. For this system, besides fluid-fluid transitions, the formation of a solid phase at low temperatures, usually below $298 \mathrm{~K}$, was also observed. Each liquid-solid equilibrium (LSE) data point was obtained by decreasing the temperature while the pressure was kept constant, so the standard deviation was presented for temperature transitions (Table 2). On the other hand, the LLE and LLVE were experimentally found by decreasing the pressure at constant temperature; consequently, the standard deviation was calculated for pressure transitions.

Figure 4 presents the $P-T$ diagram for the HFA-134a + PEG-2000 system at 1.39 wt \% PEG in the mixture. The two-

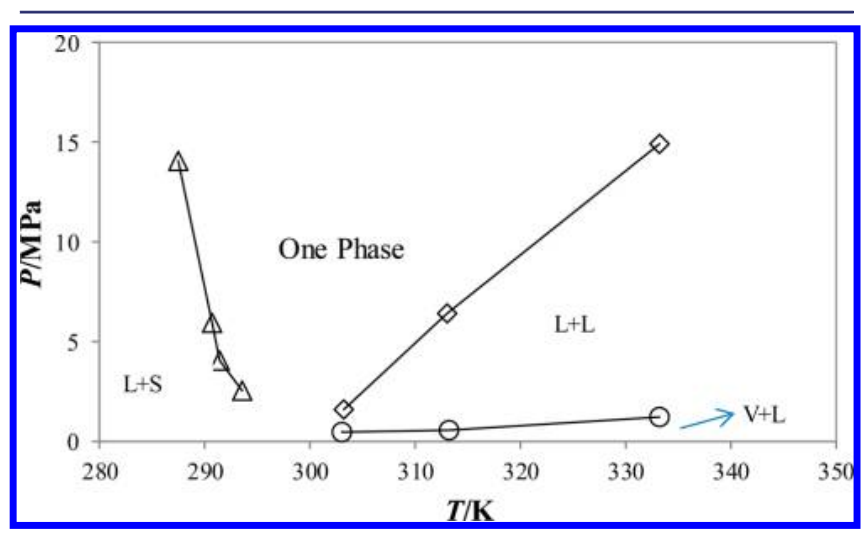

Figure 4. Phase equilibrium data for the HFA-134a + PEG-2000 (1.39 wt \%) system: $(\triangle)$ LSE, $(\diamond)$ LLE, and $(O)$ LLVE. Lines through data points are only to guide the eye. phase region below the LLVE line is of the liquid-vapor equilibrium (LVE) type. The area extending between the LLVE and LLE curves is the region of liquid-liquid immiscibility, and the area limited by the LLE curve and the LSE curve is a homogeneous region of the liquid type. In the region located to the left of the LSE curve, the system presents two phases: a liquid phase and a solid phase. The pressure values of the LLVE line are in the order of those of the vapor pressure curve of pure HFA-134a (not shown in the figure). Besides, the LLVE pressure values are relatively low in comparison to those of the LSE and LLE curves.

Solid phases were not observed for system HFA-134a + PEG-1000 within the experimental ranges of conditions. These finding suggests that the PEG molecular weight influences the temperature of solidification of the polymer when it coexists with HFA-134a in a fluid phase. From Figure 4, it seems that the LLE curve and the LSE curve should meet at a solidliquid-liquid equilibrium (SLLE) point belonging to the equilibrium phase envelope.

Figure 5 depicts, for system HFA-134a + PEG-2000, the experimental phase behavior at different PEG concentrations

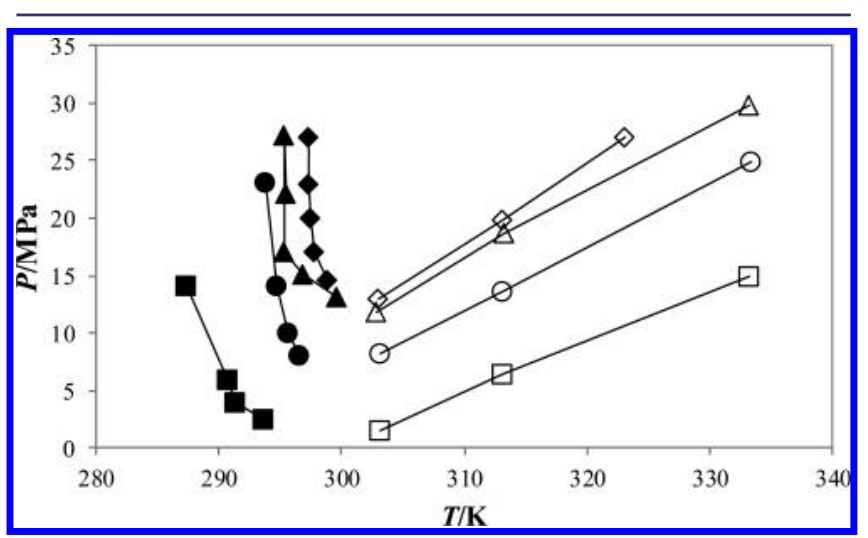

Figure 5. Phase equilibrium data (LSE and LLE) for the HFA-134a + PEG-2000 system at different temperatures, pressures, and PEG compositions: ( $\square$ ) LLE and (ם) LSE at PEG = 1.39 wt \%; (O) LLE and $(\bullet)$ LSE at PEG $=2.80$ wt $\% ;(\triangle)$ LLE and $(\mathbf{\Delta})$ LSE at PEG $=$ 3.89 wt \%; and $(\diamond)$ LLE and $(\diamond)$ LSE at PEG $=7.04$ wt $\%$. Lines connect only experimental points. Lines through data points are only to guide the eye.

$(1.39,2.80,3.89$, and 7.04 wt \%), temperatures (293 to $333 \mathrm{~K})$, and pressures (up to $30 \mathrm{MPa}$ ). It is noticed that as the PEG concentration increases, the LSE locus is shifted to higher temperatures and is in accordance with results obtained by Weidner et al. (1996) ${ }^{41}$ for systems composed of $\mathrm{CO}_{2}$ and PEG with different molar weights. Figure 5 also shows that the LLE transition curves move up in the pressure-temperature plane when the PEG-2000 content increases. Thus, higher PEG-2000 concentrations imply higher miscibility pressures of system HFA-134a + PEG-2000. The behavior of the LSE and LLE loci, shown in Figure 5, suggests that the SLLE point that would be located on the phase envelope is significantly shifted toward higher temperature and higher pressure as the PEG-2000 concentration is increased. The extrapolation of the experimental LLE and LSE curves, for a given overall PEG-2000 concentration, could provide an estimate of the temperature and pressure coordinates of the SLLE point belonging to the corresponding phase envelope.

Figure 6 presents a comparison of LVE and LLE curves for PEG-1000 and PEG-2000 in HFA-134a. It is seen that there is a 


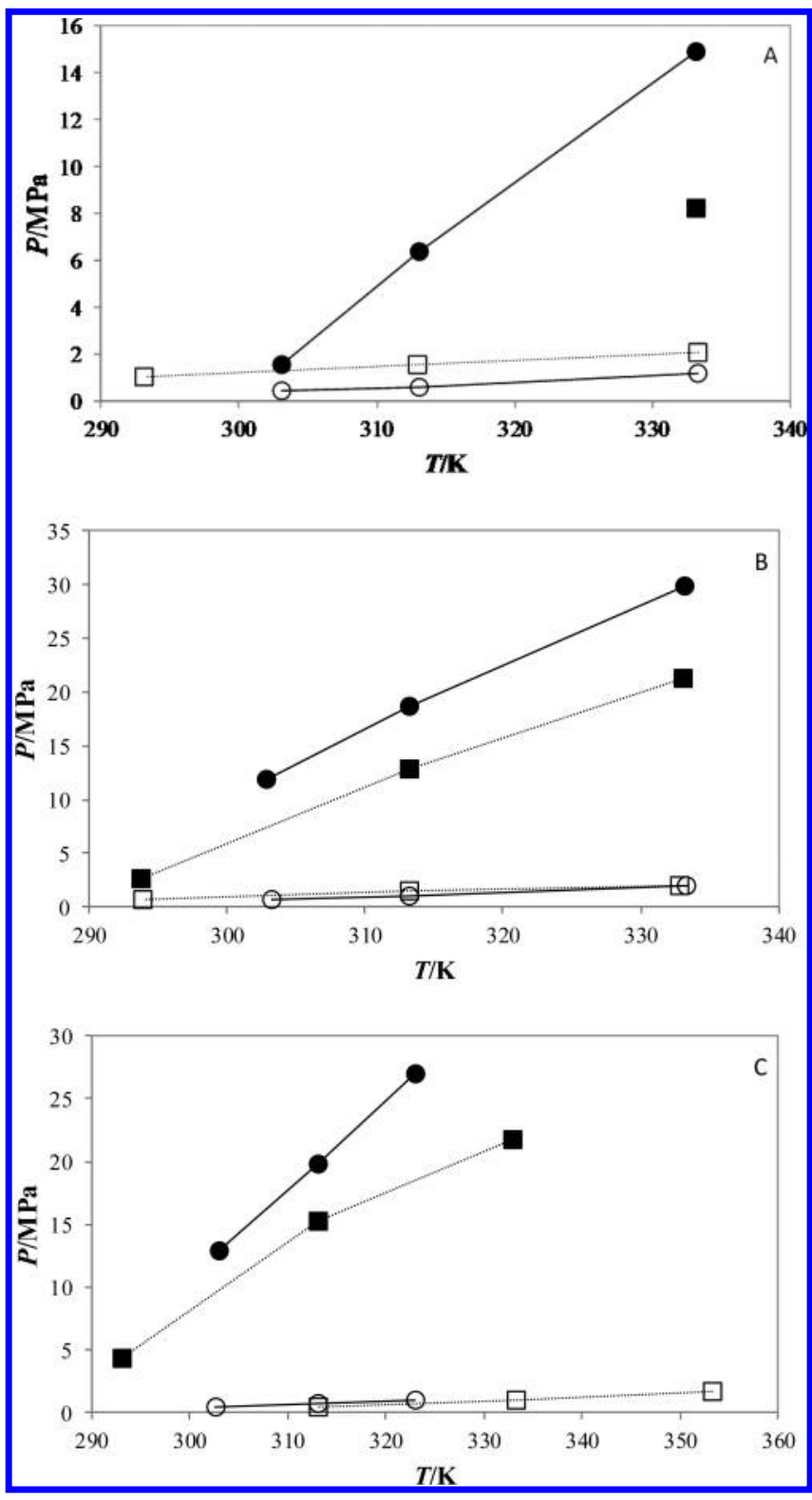

Figure 6. Comparison of LLVE and LVE data at different temperatures (293 to $333 \mathrm{~K}$ ) for systems HFA-134a + PEG-1000 (squares) and HFA-134a + PEG-2000 (circles). Solid symbols, LLE; open symbols, LLVE. (A) PEG-1000 $=1.40$ wt $\%$ and PEG-2000 $=$ 1.39 wt \%, (B) PEG-1000 $=4.74$ wt $\%$ and PEG-2000 $=3.89$ wt $\%$, and $(\mathrm{C})$ PEG-1000 $=6.95$ wt $\%$ and PEG-2000 $=7.04$ wt \%. Lines through data points are only to guide the eye.

remarkable influence of the PEG molecular weight on the HFA$134 a+$ PEG phase behavior under the conditions investigated in this work. This influence is more pronounced for the LLE curve, independent of the PEG composition. Wiesmet et al. ${ }^{41}$ investigated gas solubility in PEG in systems with PEG + propane, $\mathrm{PEG}+\mathrm{N}_{2}$, and PEG $+\mathrm{CO}_{2}$, with PEG MWs of 200, 1500,4000 , and $8000 \mathrm{~g} \cdot \mathrm{mol}^{-1}$. They have observed that the increase in PEG molecular weight of 200 to $1500 \mathrm{~g} \cdot \mathrm{mol}^{-1}$ strongly influenced the propane solubility because of the number of polymer polar end groups responsible for intermolecular association. This same behavior was also observed by Daneshvar et al. ${ }^{21}$ for $\mathrm{CO}_{2}+\operatorname{PEG}$ (400, 600, and $1000 \mathrm{~g} \cdot \mathrm{mol}^{-1}$ ) systems.
In the work of Wiesmet et al., ${ }^{41}$ as the molecular weight of the polymer increased (PEG 1500 to PEG 8000), the propane solubility was weakly influenced by polymer self-association. The same behavior was observed for the system with $\mathrm{CO}_{2}$. In the system with $\mathrm{N}_{2}$, the increase in polymer molecular weight did not influence the gas solubility because of the very low solubility of this gas in PEG. It should be emphasized that all of the cited works deal with carbon dioxide as the solvent, which is a nonpolar solvent.

For polar solvents, such as HFA-134a used in this work, it is expected that polar polymers such as PEG have considerable solubility that is influenced by the molecular weight of the polymer as a result of interactions between polymer and solvent such as dipole-dipole and hydrogen bonding. Kuk et al. ${ }^{42}$ studied the phase behavior of poly(D,L-lactide) $(\mathrm{MW}=2000$ and 30000) with four hydrofluoroalkanes with different dipole moments, including HFA-134a as the more polar of the solvents, in the temperature range of 303 to $373 \mathrm{~K}$ and at pressures from $3 \mathrm{MPa}$ up to $85 \mathrm{MPa}$. They observed that more polymer was dissolved as the dipole moment of the solvent increased and that increasing the polymer molecular weight decreased the single-phase region. This same behavior was also observed by Lee et al. ${ }^{43}$ for system L-PLA + HCFC-22.

\section{CONCLUSIONS}

The phase behavior of mixtures of refrigerant HFA-134a and a poly(ethylene glycol) (PEG, molecular weight equal to 1000 and $2000 \mathrm{~g} \cdot \mathrm{mol}^{-1}$ ) was investigated at distinct temperatures (in the range of 288 to $333 \mathrm{~K}$ ) at a PEG concentration of up to 7.5 wt $\%$ and at pressures of up to $30 \mathrm{MPa}$. The results indicated that, for both PEGs, the increases in pressure and temperature have positive and negative effects, respectively, on the solubility of PEG in HFA-134a. Liquid-solid equilibrium (LSE) was observed for temperatures below $303 \mathrm{~K}$ for system HFA-134a + PEG-2000. The results also indicated that the phase behavior of PEGs in HFA-134a is influenced by the molecular weight of the polymer.

\section{AUTHOR INFORMATION}

\section{Corresponding Author}

*Tel: +55-79-32182157. Fax: +55-79-32182190. E-mail: franceschi.elton@gmail.com.

\section{ORCID}

Elton Franceschi: 0000-0002-2675-7250

\section{Notes}

The authors declare no competing financial interest.

\section{ACKNOWLEDGMENTS}

The authors thank FAPITEC and UNIT for financial support and scholarships.

\section{REFERENCES}

(1) Jiao, Y.; Ubrich, N.; Marchand-avier, M.; Vigneron, C.; Hoffman, M.; Lecompte, T.; Maincent, P. In vitro and in vivo evaluation of oral heparin-loaded polymeric nanoparticles in rabbits. Circulation 2002, 105, 230-235.

(2) Lee, S. H.; Zhang, Z.; Feng, S.-S. Nanoparticles of poly(lactide)tocopheryl polyethylene glycol succinate (PLA-TPGS) copolymers for protein drug delivery. Biomaterials 2007, 28, 2041-2050.

(3) Selvam, P.; Bharatwaj, B.; Porcal, L.; da Rocha, S. R. P. Reverse Aqueous Microemulsions in Hydrofluoroalkane Propellants and their Aerosol Characteristics. Int. I. Pharm. 2012, 422, 428-435. 
(4) Conti, D.; Bharatwaj, B.; Brewer, D.; da Rocha, S. R. P. Propellant-based inhalers for the non-invasive delivery of genes to the lungs. I. Controlled Release 2012, 157, 406-417.

(5) Kamaly, N.; Yameen, B.; Wu, J.; Farokhzad, O. C. Degradable controlled-release polymers and polymeric nanoparticles: Mechanisms of controlling drug release. Chem. Rev. 2016, 116, 2602-2663.

(6) Jarmer, D. J.; Lengsfeld, C. S.; Randolph, T. W. Manipulation of particle size distribution of poly(L-lactic acid) nanoparticles with a jetswirl nozzle during precipitation with a compressed antisolvent. J. Supercrit. Fluids 2003, 27, 317-336.

(7) Elvassore, N.; Flaibani, M.; Bertucco, A. Thermodynamic analysis of micronization processes from gas-saturated solution. Ind. Eng. Chem. Res. 2003, 42, 5924-5930.

(8) Pathak, P.; Meziani, M. J.; Desai, T.; Foster, C.; Diaz, J. A.; Sun, Y. P. J. Supercritical fluid processing of drug nanoparticles in stable suspension. I. Nanosci. Nanotechnol. 2007, 7, 2542-2545.

(9) Sheth, P.; Sandhu, H.; Singhal, D.; Malick, W.; Shah, N.; Kislalioglu, M. S. Nanoparticles in the pharmaceutical industry and the use of supercritical fluid technologies for nanoparticle production. Curr. Druo Delivery 2012, 9, 269-284.

(10) Girotra, P.; Singh, S. K.; Nagpal, K. Supercritical fluid technology: a promising approach in pharmaceutical research. Pharm. Dev. Technol. 2013, 18, 22-38.

(11) Campardelli, R.; Baldino, L.; Reverchon, E. Supercritical fluids applications in nanomedicine. I. Supercrit. Fluids 2015, 101, 193-214.

(12) Yeo, S. D.; Kiran, E. Formation of polymer particles with supercritical fluids: A review. I. Supercrit. Fluids 2005, 34, 287-308.

(13) Duarte, A. R. C.; Duarte, C. M. R. Applications of Supercritical Expansion Processes for Particle Formation. Current Trends of the Supercritical Fluid Technology in the Pharmaceutical, Nutraceutical and Food Processing Industries; Bentham Science Publishers: New York, 2009; Chapter 2, pp 8-15. http://ebooks.benthamscience.com/book/ 9781608050468/chapter/52356/ (accessed October 25, 2015).

(14) Gwon, J.; Kim, S. H.; Shin, H. Y.; Kim, H. Phase behavior of poly(D-lactic acid), dichloromethane, and carbon dioxide ternary mixture systems at high pressure. I. Chem. Eng. Data 2014, 59, 21442149.

(15) Im, T.; Gwon, J.; Kim, S. H.; Shin, H. Y.; Kim, H. High pressure phase behavior of poly(L-lactic acid), trichloromethane, and carbon dioxide ternary mixture systems. I. Chem. Eng. Data 2015, 60, 21722177.

(16) Schacht, C. S.; Schuell, C.; Frey, H.; De Loos, T. W.; Gross, J. Phase behavior of the system linear polyglycerol + methanol + carbon dioxide. I. Chem. Eng. Data 2011, 56, 2927-2931.

(17) Rojo, S. R.; Martín, A.; Calvo, E. S.; Cocero, M. J. Solubility of polycaprolactone in supercritical carbon dioxide with ethanol as cosolvent. I. Chem. Eng. Data 2009, 54, 962-965.

(18) Im, T.; Gwon, J.; Kim, S. H.; Shin, H. Y.; Kim, H. High-Pressure Phase Behavior of Poly(D-Lactic Acid), Trichloromethane, and carbon dioxide ternary mixture systems. I. Chem. Thermodyn. 2015, 90, 216223.

(19) Yue, B.; Yang, J.; Wang, Y.; Huang, C.-Y.; Dave, R.; Pfeffer, R. Particle encapsulation with polymers via in situ polymerization in supercritical $\mathrm{CO}_{2}$. Powder Technol. 2004, 146, 32-45.

(20) Byun, H. S.; Lee, D. H.; Lim, J. S.; Yoo, K. P. Phase behavior of binary and ternary mixtures of biodegradable poly $(\varepsilon$-caprolactone $)$ in supercritical fluids. Ind. Eng. Chem. Res. 2006, 45, 3366-3372.

(21) Daneshvar, M.; Kim, S.; Gulari, E. High-pressure phase equilibria of poly(ethylene glycol) - carbon dioxide systems. J. Phys. Chem. 1990, 94, 2124-2128.

(22) Yang, Z. Z.; Song, Q. W.; He, L. N. Capture and Utilization of Carbon Dioxide with Polyethylene Glycol; SpringerBriefs in Molecular Science, Green Chemistry for Sustainability; Springer: New York, 2012; Chapter 2, pp 7-15. http://link.springer.com/book/10.1007/ 978-3-642-31268-7 (accessed October 9, 2015).

(23) Corr, S. 1,1,1,2-Tetrafluoroethane; from refrigerant and propellant to solvent. I. Fluorine Chem. 2002, 118, 55-67.

(24) Zehioua, R.; Coquelet, C.; Meniai, A. H.; Richon, D. Isothermal Vapor-Liquid Equilibrium Data of 1,1,1,2-Tetrafluoroethane (R134a)
+ Dimethylformamide (DMF) Working Fluids for an Absorption Heat Transformer. I. Chem. Eng. Data 2010, 55, 985-988.

(25) Hansen, E.; Pedersen, H.; Christensen, M. F.; Feilberg, K. L.; Warming, M. Survey of Selected Fluorinated Greenhouse Gases; The Danish Environmental Protection Agency: Copenhagen, 2015; Chapter 7, pp 92-110. http://www2.mst.dk/Udgiv/publications/ 2015/02/978-87-93283-82-4.pdf (accessed April 18, 2016).

(26) Owell, G. M. In Handbook of Water-Soluble Gums and Resins; Davidson, R. L., Ed.; McGraw-Hill: New York, 1980; Polyethylene Glycol, cap. 18.

(27) Liu, L.; Wang, X. Improved dissolution of oleanolic acid with ternary solid dispersions. AAPS PharmSciTech 2007, 8, 267-271.

(28) Patel, R. P.; Patel, D. J.; Bhimani, D. B.; Patel, J. K. Physicochemical characterization and dissolution study of solid dispersions of furosemide with polyethylene glycol 6000 and polyvinylpyrrolidone K-30. Dissolution Technol. 2008, 15, 17-25.

(29) Gullapalli, R. P. Soft gelatin capsules (softgels). J. Pharm. Sci. 2010, 99, 4107-4148.

(30) Gullapalli, R. P.; Mazzitelli, C. L. Polyethylene glycols in oral and parenteral formulations-A critical review. Int. J. Pharm. 2015, 496, 219-239.

(31) Tenório Neto, E. T.; Kunita, M. H.; Rubira, A. F.; Leite, B. M.; Dariva, C.; Santos, A. F.; Fortuny, M.; Franceschi, E. Phase equilibria of the systems $\mathrm{CO}_{2}+$ styrene, $\mathrm{CO}_{2}+$ safrole, and $\mathrm{CO}_{2}+$ styrene + safrole. I. Chem. Eng. Data 2013, 58, 1685-1691.

(32) Borges, G. R.; Junges, A.; Franceschi, E.; Corazza, F. C.; Corazza, M. L.; Oliveira, J. V.; Dariva, C. High-pressure vapor-liquid equilibrium data for systems involving carbon dioxide + organic solvent + b-carotene. I. Chem. Eng. Data 2007, 52, 1437-1441.

(33) Esmelindro, M. C.; Antunes, O. A. C.; Franceschi, E.; Borges, G. R.; Corazza, M. L.; Oliveira, J. V.; Linhares, W.; Dariva, C. Phase behavior of reactant and products of cyclohexane oxidation in compressed $\mathrm{CO}_{2}$. I. Chem. Eng. Data 2008, 53, 2050-2055.

(34) McHugh, M. A.; Krukonis, V. J. Supercritical Fluid Extraction: Principles and Practice, 2nd ed.; Butterworth-Heinemann: Boston, 1994.

(35) Favareto, R.; Cabral, V. F.; Corazza, M. L.; Cardoso Filho, L. Vapor-liquid and solid-fluid equilibrium for progesterone plus $\mathrm{CO}_{2}$, progesterone plus propane, and progesterone plus n-butane systems at elevated pressures. I. Supercrit. Fluids 2008, 45, 161-170.

(36) Portela, V. M.; Straver, E. J. M.; de Loos, Th. W. High-pressure phase behavior of the system propane - boltron H3200. J. Chem. Eng. Data 2009, 54, 2593-2598.

(37) Grandelli, H. E.; Kiran, E. High pressure density, miscibility and compressibility of poly(lactide-co-glycolide) solutions in acetone and

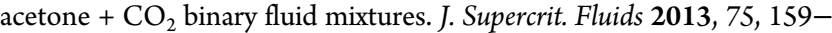
171

(38) Park, J. Y.; Kim, S. Y.; Byun, H. S.; Yoo, K. P.; Lim, J. S. Cloud points of poly(e-caprolactone), poly(L-lactide), and polystyrene in supercritical fluids. Ind. Eng. Chem. Res. 2006, 45, 3381-3387.

(39) Martin, T. M.; Gupta, R. B.; Roberts, C. B. Measurements and modeling of cloud point behavior for poly(propylene glycol) in ethane and in ethane + cosolvent mixtures at high pressure. Ind. Eng. Chem. Res. 2000, 39, 185-194.

(40) Paul, A.; Talbot, G. L.; Bowles, J. W.; James, J.; Griffiths, P. C.; Rogueda, P. G. Partitioning and phase equilibria of PEGylated excipients in fluorinated liquids. Int. I. Pharm. 2010, 387, 230-235.

(41) Wiesmet, V.; Weidner, E.; Behme, S.; Sadowski, G.; Arlt, W. Measurement and modelling of high-pressure phase equilibria in the systems polyethyleneglycol (PEG)-propane, PEG-nitrogen and PEG-carbon dioxide. I. Supercrit. Fluids 2000, 17, 1-12.

(42) Wiesmet, V.; Weidner, E.; Behme, S.; Sadowski, G.; Arlt, W. Measurement and modelling of high-pressure phase equilibria in the systems polyethyleneglycol (PEG) - propane, PEG-nitrogen and PEG-carbon dioxide. I. Supercrit. Fluids 2000, 17, 1-12.

(43) Lee, J. M.; Lee, B. C.; Lee, S. H. Cluod points of biodegradable polymers in compressed liquid and supercritical chlorodifluoromethane. I. Chem. Eng. Data 2000, 45, 851-856. 